\title{
A EDUCAÇÃO AMBIENTAL COMO INSTRUMENTO DE SENSIBILIZAÇÃO PARA OS GESTORES DA HOTELARIA
}

\author{
Mary Lúcia Gomes Silveira de Senna ${ }^{1}$ \\ Ana Julyah Gonçalves Valtuille ${ }^{2}$
}

Resumo: A capital Palmas concentra hoje um grande número de hotéis. Se por um lado aumenta a geração de renda e emprego, por outro gera também a preocupação em relação à geração de impactos ambientais na região. Desta forma, esse trabalho propôs por meio de ações de educação ambiental, capacitar os gestores hoteleiros sobre a ABNT NBR 1540, para que se torne uma hotelaria com selo sustentável. Ao longo do estudo realizado percebeu-se que não houve, a princípio, interesse por parte dos proprietários e gerentes em realizar a ação educativa. Mas após mudar-se a estratégia por visitas in loco, os representantes hoteleiros visitados se mostraram interessados, mas justificaram a dificuldade em investir neste segmento ambiental.

Palavras-chave: Turismo; Sustentabilidade; Educação Ambiental, Hotéis; ABNT NBR 15401.

Abstract: Palmas concentrates many hotels of Tocantins State. This increases the generation of income and employment increases, on the other it also generates concern regarding the generation of environmental impacts in the region. In this way, this study proposed, through environmental education actions, to train hotel managers on ABNT NBR 1540, so that it becomes a hotel with a sustainable seal. Throughout the study, it was noticed that there was, at first, no interest on the part of the owners and managers in carrying out the educational action. But after changing the strategy for on-site visits, the hotel representatives visited were interested, but justified the difficulty in investing in this environmental segment.

Keywords: Tourism; Sustainability; Environmental Education; Hotels; ABNT NBR 15401.

\footnotetext{
1 Instituto Federal de Educação, Ciência e Tecnologia do Tocantins, Palmas, TO.

E-mail: marysenna@ifto.edu.br, Link para o Lattes: http://lattes.cnpq.br/1745769805611202

2 Instituto Federal de Educação, Ciência e Tecnologia do Tocantins, Palmas, TO.

E-mail: juhvaltuille757@gmail.com, Link para o Lattes: http://lattes.cnpq.br/9527865847307430
} 


\section{Introdução}

Vivemos em um mundo globalizado em que o consumo de bens está cada vez maior. A hotelaria vem consumindo grandes quantidades de energia, água e produtos não duráveis que, consequentemente, geram efluentes, resíduos e emissões, tornando-se fonte de impactos ambientais (BERNADELLI JR et al., 2014, p. 566).

A identificação destes impactos é importante à medida que uma vez diagnosticado a sua existência, é possível buscar ações para minimizá-lo posteriormente. Sant'Anna e Zambonim (2002 apud BERNADELLI JR et al., 2014 , p. 566) afirmam que a maioria dos impactos ambientais associados ao setor hoteleiro pode ser minimizada por meio de medidas administrativas e gerenciais que sejam de forma preventiva e com o uso de tecnologias limpas.

Além disso, a análise seguida de medidas mitigatórias destes impactos pode contribuir significativamente com a qualidade de vida das pessoas que residem no local (SENNA, 2016, p. 44).

Ainda sobre as vantagens de se minimizar os impactos na hotelaria está também na valorização do produto hoteleiro para o empresário que assim investe nestas ações mitigatórias. Isto quer dizer que hotéis com gestão hoteleira tendem a possuir um diferencial em seu produto de vendas, pois muitos clientes optam por reservarem hotéis que associem em sua marca o selo ambiental, tal como descreve Bernadelli Jr. et al. (2014, p. 573). Portanto a utilização de estratégias voltadas para o marketing ambiental pelos meios de hospedagem pode, na verdade, significar um grande fator de diferenciação e proporcionar vantagem competitiva para as empresas do segmento turístico.

Acredita-se que práticas muito mais complexas e completas poderiam ser realizadas pela hotelaria sustentável. A Educação Ambiental, por meio das ferramentas de marketing sugeridas tende a ser um caminho adequado na tentativa de proporcionar uma hotelaria sustentável para todos os stakeholders (pessoa ou grupo que tem interesse em uma empresa, negócio, podendo ter ou não um investimento neles) dos meios de hospedagem que adotaram o marketing ambiental como filosofia (PEREIRA, 2016, p. 104). Entretanto, como apontado anteriormente, essas ações de Educação Ambiental ainda se apresentam de forma muito precária e isolada.

A partir desta premissa, o presente estudo buscou capacitar os gestores da rede hoteleira de Palmas de modo a sensibilizá-los sobre a importância da preservação ambiental de acordo com a NBR 15.401, bem como, mostrou as principais vantagens econômicas para o estabelecimento hoteleiro ao aderir um modelo de empresa sustentável.

Segundo os dados de Paula $(2018$, p.13) o segmento hoteleiro da cidade de Palmas (TO) tem crescido, principalmente quanto a estrutura e oferta de novas unidades habitacionais nos hotéis da Capital. Segundo a autora, os novos empreendimentos trouxeram um incremento de mais de 1000 leitos para a cidade, ou seja, um crescimento de $34,77 \%$. 
E esse crescimento na rede hoteleira, gera diversas preocupações. Dentre elas destaca-se como são monitorados os impactos ambientais gerados pela rede hoteleira na cidade ou se estes possuem algum sistema de gestão sustentável em seu estabelecimento. O trabalho de Barbosa e Santos (2018, p. 47) mostrou que apesar de algumas ações pontuais realizadas pela rede hoteleira de Palmas, ainda há a necessidade de maior sensibilização dos gestores da rede principalmente quanto, a investimento em captação da água da chuva, reciclagem de resíduos sólidos, ações em prol de proteção de espécies e conscientização de hóspedes quanto ao respeito às tradições e costumes locais.

Logo, a pesquisa surgiu com o intuito de capacitar os gestores da rede hoteleira de Palmas de modo a sensibilizá-los sobre a importância da preservação ambiental de acordo com a NBR 15.401, bem como, mostrar as principais vantagens econômicas para o estabelecimento hoteleiro ao aderir um modelo de empresa sustentável.

Segundo Sereno et al. (2014, p.76) a implantação de um Sistema de Gestão Ambiental (SGA) é uma fase para a gestão sustentável na hotelaria. Sua implantação implica melhorar o desempenho ambiental das empresas, tendo como base a redução de desperdícios de água, fazendo seu uso de maneira racional, ou a utilização de fontes de energia alternativa e matéria-prima. Algumas práticas também podem oferecer economia para o estabelecimento e, assim, todos os envolvidos no turismo podem colaborar e participar.

A certificação, nos serviços de hotelaria, vem sendo bastante difundida, especialmente por dois motivos: porque as discussões sobre os ambientes estão bastante avançadas e aos poucos a sociedade, os clientes estão se tornando cada vez mais conscientes e acabam cobrando alternativas mais viáveis e menos impactantes ao espaço onde o empreendimento está inserido (MORAES, 2009, p.14).

Contudo cabe aos gestores, o ato de implantação e adequação dentro do meio hoteleiro, e ao visitante a preferência em meios que garanta qualidade na hospedagem e respeito ao meio ambiente. O setor público deve oferecer incentivos a ações como essas, motivando os demais hotéis a qualificação e posteriormente reduzindo os impactos em massa gerada na região.

\section{Desenvolvimento Sustentável}

O uso sustentável dos recursos naturais é um dos principais desafios da atualidade, esse tema tem mobilizado diversas organizações a discutir alternativas, formas e métodos de como utilizar esses recursos de forma racional para que atenda às necessidades atuais sem deixar de comprometer o desenvolvimento das futuras (LADWIG, 2012, p. 20).

Desde a década de 1980, o tema desenvolvimento sustentável tornou-se um termo relevante e periódico nos estudos sobre o desenvolvimento, numa abordagem mais geral, e nos estudos sobre turismo principalmente e apesar 
dessas discussões não terem gerado inovações radicais, provocaram uma reorientação no planejamento e gestão do turismo (CORDEIRO; KÖRÖSSY, 2018, p. 44).

Apesar desse tema ser defendido como relevante e necessário, sendo um consenso entre muitos governos e entidades ligados ao turismo, sendo inclusive discutido em diversos espaços, se percebe que ele não tem sido implementado na prática de forma satisfatória quando se verifica os planejamentos e legislações estabelecidas. Segundo Cordeiro e Körössy (2018 p.44) esse fato pode ser explicado pela dificuldade da aplicação da política de desenvolvimento sustentável que envolva a rede de (empresários, consumidores, produtores e governos e órgãos de controle e fomento).

Existe um grande impasse entre as doutrinas de desenvolvimento sustentável com a sua aplicação na realidade. Elas se esbarram em diversos interesses que muitas vezes não levam em consideração os aspectos ecológicos e sustentáveis, muitos estão voltados para a lucratividade e ainda não conseguem entender o desenvolvimento sustentável como um aliado ao seu negócio, tendo ainda a visão de que é um empecilho para seu crescimento. (CASTRO; PINTO, 2013, p.224)

As normas ISO 9001 e 14001 são muito semelhantes entre si, possuindo objetivos similares e utilizando ferramentas em comum (GRAEL e OLIVEIRA, 2010, p. 32). Ambos os sistemas se baseiam na metodologia PDCA - Plan, Do, Check and Act, apresentada de forma esquemática na Figura 1. De acordo com Matthews (2003), o uso deste método segue os seguintes processos: i) planejar: políticas, impactos e metas ambientais; ii) executar: atividades ambientais e documentação ambiental; iii) verificar: auditorias ambientais e avaliação de desempenho ambiental e iv) agir: treinamento e comunicação ambiental.

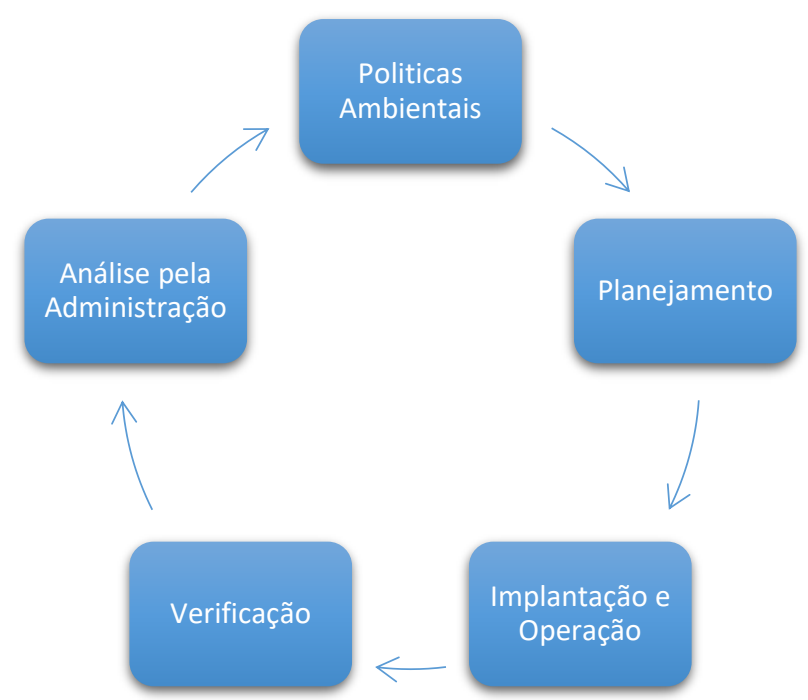

Figura 1: Fluxograma da metodologia PDCA.

Fonte: Adaptado de Grael e Oliveira (2010, p.34). 


\section{Turismo Sustentável}

A Organização Mundial do Turismo - OMT (2005, p.1), define turismo sustentável como um processo que atende às necessidades atuais dos turistas e das comunidades receptoras, sem comprometer a capacidade de atender as necessidades das gerações futuras. Desta forma, a atividade do turismo não poderia negligenciar os princípios de desenvolvimento sustentável, tendo em vista que grande parte das atividades turísticas utiliza o meio ambiente como recurso de desenvolvimento. Assim, torna-se essencial que, além de atender demandas do público atual, também atendam a demanda futura.

O conceito de turismo sustentável diz respeito ao equilíbrio nas relações entre o turismo e meio ambiente e na minimização de conflitos entre as partes envolvidas de forma que se garanta a viabilidade da atividade e harmonia entre eles para que se tenha uma qualidade e durabilidade. Esse conceito não pode ser confundido com modalidade de turismo como turismo cultural, de aventura ou indígena entre outros (BRANDAO; BARBIERI; REYES JUNIOR, 2015, p.503).

Para que o turismo sustentável possa se desenvolver de forma harmônica é necessário haver a participação de todos os interessados, como cidadãos, empresários e líderes comunitários pois além de garantir concessão das decisões torna o os envolvidos mais capazes de lidar com os vários problemas que surgirem (SILVA; CÂNDIDO, 2016, p. 477).

O turismo sustentável só é possível através de planejamento e monitoramento das medidas, decisões que foram implantas com metas claras e coerentes sem perder os princípios da utilização ótima dos recursos ambientais; respeitar a autenticidade sociocultural das comunidades anfitriãs, conservar o seu patrimônio cultural e valores tradicionais; é importante também que todos os benefícios sejam distribuídos estre todos os envolvidos de forma justa.(BRANDAO; BARBIERI; REYES JUNIOR, 2015, p. 504)

\section{Impactos do turismo na rede hoteleira}

A atividade turística causa efeitos em três grandes dimensões: ambiental, sociocultural e econômica. No aspecto econômico destaca-se o aumento das receitas, aumento do recebimento de divisas, geração de empregos, estímulos aos investimentos, redistribuição de renda e geração de impostos (REZENDE; REZENDE, 2015, p.3).

Segundo Butler (2008 apud PERES JR; REZENDE, 2011, p.241) apesar de ser incipiente o desenvolvimento sustentável na indústria hoteleira, essas tendências levarão ao desenvolvimento de "hotéis verdes". O autor ainda afirma que aqueles que adotarem posturas ambientalmente corretas voluntariamente, antes que elas se tornem normas impostas, serão recompensadas pelo mercado.

Enquanto a indústria do turismo está muito preocupada com benefícios extraordinários e ações startup e isoladas para o desenvolvimento sustentável, 
determinadas principalmente pela lei ou redução de custos, alguns hotéis já estão começando a implementar procedimentos em suas ações que visam reduzir seu impacto social e ambiental (BORGES, 2015, p.603).

\section{ABNT NBR 15.401 Meios de hospedagem sistema de gestão da sustentabilidade}

A NBR 15401 foi criada para o setor de turismo em novembro de 2006 e visa estabelecer requisitos para instalações de acomodação que permitam planejar e executar atividades de acordo com os princípios do turismo sustentável (ASSUNÇÃO; AMORIM; MONDO, 2013, p. 279).

A norma se aplica a todos os tipos e tamanhos da organização e se adapta a diferentes condições geográficas, culturais e sociais, com ênfase especial na realidade e na possibilidade de usar pequenas e médias empresas. Define os requisitos objetivos que podem ser usados tanto para fins de certificação como para autoavaliação de apostas (ASSUNÇÃO; AMORIM; MONDO, 2013, p.279).

Abordar a padronização do desenvolvimento sustentável do turismo e a possibilidade resultante da aplicação dos sistemas de certificação de negócios, que aplicam os padrões relacionados, começa com o estabelecimento de requisitos de desempenho para as dimensões da sustentabilidade (ambiental, social, cultural e econômico) que é apoiado por um sistema de gestão da sustentabilidade. Esse sistema de gerenciamento fornece uma base estável, coerente e consistente para o desempenho e a manutenção de negócios sustentáveis (ABNT, 2006, p.6).

Esta norma define os requisitos para a celebração, que lhe permitirá planejar e realizar operações de acordo com as regras estabelecidas para o turismo sustentável, que foi desenvolvido de forma que se aplique a todos os tipos e tamanhos de organizações e se adapte às diferentes situações geográficas, culturais e sociais, mas com particular ênfase na realidade e as possibilidades de aplicação em pequenas e médias empresas (ABNT, 2006, p.6).

\section{Educação Ambiental em ação}

O ser humano vivia uma relação harmônica com a natureza e dela retirava o necessário para a sobrevivência da espécie, mas com o passar dos anos e o desenvolvimento das ciências, o homem começou usar a natureza em benefício próprio. Tal evolução provocou um grande avanço nas condutas inadequadas referentes ao meio ambiente, principalmente por meio do desperdício e da degradação ambiental.

Segundo Ferreira et. al. (2019 p.202) a Educação Ambiental é responsável por estimular a conscientização do indivíduo em relação aos problemas ambientais, e define como diretrizes para combatê-los, principalmente por meio 
da conservação das reservas naturais. É uma perspectiva da educação direcionada a assuntos que ligam a interação homem-ambiente, e visa despertar uma consciência crítica sobre os problemas ambientais. Para estimular também o indivíduo a desenvolver um caráter mais complexo e realista, considerando o ambiente em sua totalidade.

Ferreira et. al. (2019, p.202) ainda destaca que nessa sociedade de risco, as figuras do consumidor e do cidadão são diretamente atreladas, sendo impossível a dissociação. Assim, é possível notar comportamentos distintos de consumo, como o consumo verde e o sustentável, que, quando devidamente interpretados pela visão da cidadania, chegam ao eco consumo.

Leite (2012, p.168) considera que o ambiente é tratado como bem de interesse comum no regime constitucional brasileiro, compartilhando o Estado e a coletividade, a responsabilidade de sua proteção. Neste sentido, Benjamin (2012, p.101), destaca que:

A verbalização do discurso constitucional de proteção do Ambiente não anuncia, como desiderato principal, um non facere; ao contrário, inegavelmente prega e exige prestações positivas a cargo do Estado, mensagem irrecusável que vem em reforço dos deveres infraconstitucionais de garantia pelas autoridades públicas dos processos ecológicos essenciais.

A Educação Ambiental procura, de acordo com Rodrigues e Fabris (2011, p.36) tocar o aluno gradativamente, conscientizando-o sobre o respeito, não só para com a sua cultura e a sua comunidade, mas também a diversidade e 0 planeta.

\section{Metodologia}

A presente pesquisa caracteriza-se como tipologia exploratória por proporcionar maior familiaridade com um dado problema de forma a torná-lo mais explícito. Segundo Gil (1999, p. 27) o seu planejamento é muito flexível de modo a possibilitar a consideração dos mais variados aspectos relativos ao fato estudado. Segundo o autor, em sua maioria, estas pesquisas envolvem levantamento bibliográfico, entrevistas com pessoas que tiveram experiência prática com o problema pesquisado ou ainda a análise de exemplos que estimulem a compreensão dos fatos.

Logo, em um primeiro momento foi feito um contato prévio com os órgãos regulamentadores do turismo local, tais como a SEDEN - Secretaria Estadual de Desenvolvimento Econômico, Ciência, Tecnologia, Turismo e Cultura do Tocantins, bem como, com a ABIH - Associação Brasileira da Indústria de Hotéis no Tocantins para buscar apoio para a mobilização local dos representantes hoteleiros, bem como, termos o número e contato dos hotéis cadastrados no sistema.

Revbea, São Paulo, V. 15, № 1: 360-378, 2020. 
Após isso, buscou-se realizar pesquisas bibliográficas atualizadas sobre a temática de modo a oferecer a capacitação plena aos envolvidos. Iniciou-se então o contato com cada um dos gerentes hotéis oferecendo a capacitação gratuita aos mesmos com certificação pelo IFTO.

Foi criado um folder explicativo para eles (Tabela 1), entregue no dia da capacitação que continha as seguintes diretrizes:

Tabela 1: Ações para o turismo sustentável.

\begin{tabular}{|c|c|}
\hline $\begin{array}{c}\text { Princípios do } \\
\text { Turismo Sustentável }\end{array}$ & Exemplo de Ações \\
\hline $\begin{array}{l}\text { 1. Respeitar a } \\
\text { legislação vigente }\end{array}$ & $\begin{array}{l}\text { - Ter o empreendimento registrado no CADASTUR; } \\
\text { - Possuir um sistema de tratamento de esgoto; } \\
\text { - Assegurar que os salários pagos atendam no mínimo aos pisos } \\
\text { da categoria dos colaboradores contratados, usando referências } \\
\text { sindicais regionais. }\end{array}$ \\
\hline $\begin{array}{l}\text { 2. Garantir os } \\
\text { direitos das } \\
\text { populações locais }\end{array}$ & $\begin{array}{l}\text { - Dar preferência à população local para contratação; } \\
\text { - Oferecer capacitação e treinamentos voltados para os } \\
\text { colaboradores e comunidade local; } \\
\text { - Estabelecer salários que não desvalorizem os colaboradores } \\
\text { pertencentes à comunidade. }\end{array}$ \\
\hline $\begin{array}{l}\text { 3. Conservar o } \\
\text { ambiente natural e } \\
\text { sua biodiversidade }\end{array}$ & $\begin{array}{l}\text { - Realizar ações específicas para proteção de espécies ameaçadas } \\
\text { existentes na propriedade do meio de hospedagem } \\
\text { - Implementar ações educativas com os clientes, por exemplo, a } \\
\text { conscientização quanto a não alimentação de animais silvestres } \\
\text { - Controlar a utilização dos recursos naturais pelo meio de } \\
\text { hospedagem. Por exemplo, através de manutenções periódicas do } \\
\text { encanamento para evitar o desperdício de água. }\end{array}$ \\
\hline $\begin{array}{l}\text { 4. Considerar o } \\
\text { patrimônio cultural e } \\
\text { valores locais }\end{array}$ & $\begin{array}{l}\text { - Ceder espaço do empreendimento para eventos culturais; } \\
\text { - Conscientizar o cliente quanto aos costumes locais. por exemplo, } \\
\text { para que não haja desrespeito às tradições locais e sítios sagrados. }\end{array}$ \\
\hline $\begin{array}{l}\text { 5. Estimular o } \\
\text { desenvolvimento } \\
\text { social e econômico } \\
\text { dos destinos } \\
\text { turísticos }\end{array}$ & $\begin{array}{l}\text { - Promover os produtos e serviços locais, por exemplo, indicar } \\
\text { passeios realizados por um guia responsável da região. } \\
\text { - Utilizar produtos provenientes de fornecedores pertencentes à } \\
\text { comunidade local, por exemplo, alimentos produzidos em hortas e } \\
\text { fazendas da região. }\end{array}$ \\
\hline $\begin{array}{l}\text { 6. Garantir a } \\
\text { qualidade dos } \\
\text { produtos, processos } \\
\text { e atitudes }\end{array}$ & $\begin{array}{l}\text { - Possuir um meio de comunicação aberto a sugestões e } \\
\text { reclamações; } \\
\text { - Responder prontamente as reclamações; } \\
\text { - Oferecer a descrição clara de seus produtos e serviços }\end{array}$ \\
\hline $\begin{array}{l}\text { 7. Estabelecer o } \\
\text { planejamento e a } \\
\text { gestão responsáveis }\end{array}$ & $\begin{array}{l}\text { - Estabelecer e divulgar uma Política de Sustentabilidade; } \\
\text { - Envolver os colaboradores em ações e atividades ligadas à } \\
\text { sustentabilidade; } \\
\text { - Estabelecer critérios para a contratação dos seus fornecedores }\end{array}$ \\
\hline
\end{tabular}
Fonte: ABNT (2012, p. 10).

No final foram capacitados e orientados $60 \%$ da rede hoteleira de Palmas de modo a contribuir com ações de Educação Ambiental voltada para este segmento 


\section{Resultados e Discussões}

A pesquisa teve início no segundo semestre de 2018 quando foram realizados estudos a respeito do tema e o que havia sido discutido sobre a temática. Foram encontrados alguns trabalhos específicos sobre a hotelaria de Palmas, como os de Paula (2018) e Barbosa e Santos (2018). Especialmente este último trabalho serviu como base para esta presente pesquisa, pois tornouse uma sequência do mesmo, por perceber-se na época que havia lacunas a serem trabalhados no que se refere a gestão sustentável.

Paula (2018, p.24) destaca que, segundo dados da Agência Municipal de Turismo (AGTUR) a cidade de Palmas conta atualmente com 56 meios de hospedagem, dentre eles 48 hotéis e 8 pousadas. Deste total, a capital conta hoje com 2.308 Unidades Habitacionais (UH's) e 5.137 leitos, distribuídos entre o Plano Diretor, Região Sul e o Distrito de Taquaruçu, localizado a $30 \mathrm{Km}$ do Centro de Palmas. Entretanto, desse total de 56 Meios de Hospedagem, apenas 46 estão cadastrados no Cadastro de Equipamentos e Serviços Turísticos do Ministério do Turismo (CADASTUR).

Para se confirmar tais dados, uma das primeiras etapas da pesquisa consistia em obter informações com o órgão governamental local, a Secretaria Estadual da Indústria, Comércio e Serviços (SEDEN) sobre o quantitativo e contatos dos hotéis em Palmas/TO para que o objetivo deste trabalho fosse alcançado. Percebeu-se que embora a região tenha muitos hotéis que recepcionam uma grande quantidade de hóspedes por ano, devido a boa localização da cidade, não há muitos estudos e pesquisas sobre esse setor. Acredita-se que um dos motivos é a falta de interesse da população e principalmente das instituições locais de ensino, fazendo com que dificulte o acesso a objeto de estudo.

No final do ano de 2018 foi realizado contato com a SEDEN que disponibilizou uma relação com contatos telefônicos e por e-mails dos hotéis cadastrados. Se comparados aos resultados encontrados por Paula (2018, p. 24), percebeu-se que houve um crescimento na oferta dos hotéis na capital. Este número aumentou para 49 estabelecimentos cadastrados no Cadastur, segundo dados disponibilizados pela SEDEN. Porém, ao iniciarmos os primeiros contatos, percebeu-se que alguns estavam desatualizados. Isto nos leva a crer que não há um acompanhamento entre o órgão estadual regulador e os prestadores de serviços hoteleiros. Isto pode gerar um grande desencontro na comunicação, tanto conosco pesquisadores, como também os hóspedes que tem acesso a essa relação por meio do órgão regulador.

De posse destes contatos iniciou-se o chamamento para a capacitação. Acredita-se que seria um momento mais enriquecedor se houvesse 0 compartilhamento de ideias e soluções para todos os envolvidos no trade hoteleiro. Por esta razão, optou-se em fornecer três dias de capacitação com duração de 4 horas no total, podendo o gestor do hotel escolher o dia e hora que melhor se adequasse a sua realidade. Vale destacar que em todos os dias era disponibilizado em turnos distintos para que pudesse atender a todos os públicos 
distintos. Foi criada uma arte para a primeira chamada do evento, tendo como objetivo despertar o interesse e curiosidade de que seria oferecido (Figura 2).

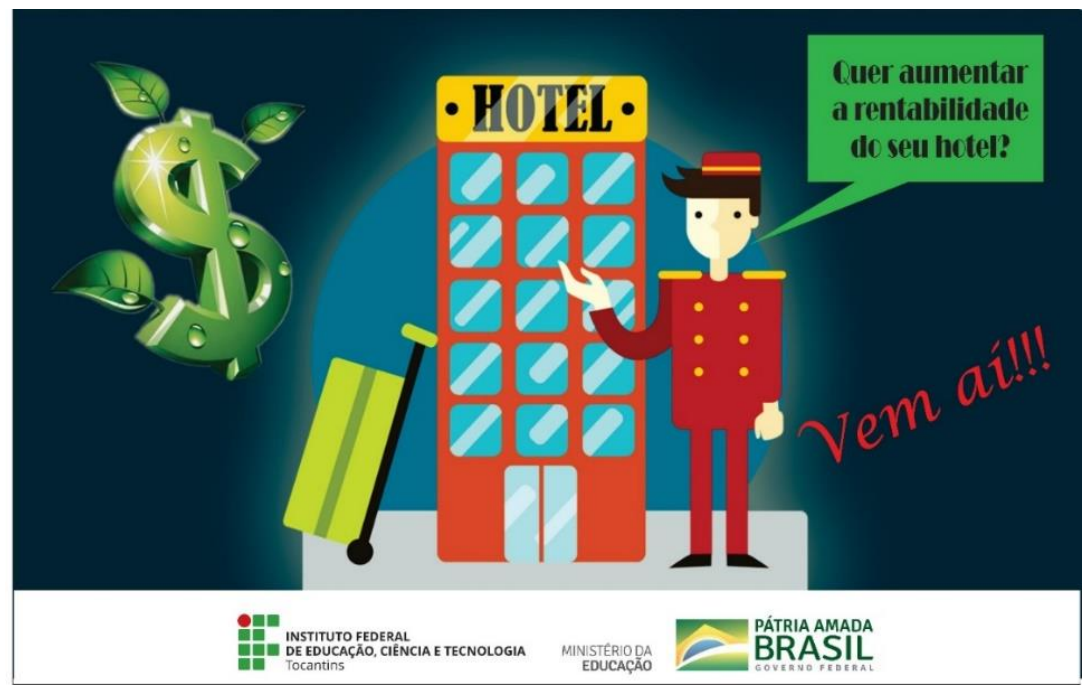

Figura 2: Convite palestra.

Fonte: Jornalismo IFTO - Campus Palmas.

Esta mensagem foi encaminhada para o e-mail dos contatos passados pela Seden trinta e vinte dias antes do evento estar programado. Faltando 15 dias do evento, foi encaminhado outro e-mail explicativo detalhando a ação educacional. Estas ações foram realizadas, pois Oliveira e Saraiva (2019, p.593) o Marketing digital é um meio eficaz de "promover produtos ou marcas nas mídias online, de forma específica para cada consumidor, gerando relacionamento e promovendo fidelização". Neste e-mail encaminhado, havia um convite oficial da Direção do campus Palmas para a realização do evento (Figura 3, próxima página).

Deste total de e-mails, sete voltaram por não serem contatos atualizados. Aguardou-se três dias por ligações voluntárias para inscrição no curso. Ao final do terceiro dia, tinha-se três inscritos. Por considerarmos o número aquém do esperado, optou-se por realizar a ligação telefônica, por acreditar que assim, pudesse ter um resultado mais satisfatório. Foram contatados os 48 hotéis da relação encaminhada pela SEDEN. Em todos os contatos existentes explicou-se a ação ambiental e foi pedido que sugerissem um nome, frisando que ao final haveria certificação aos participantes, bem como, sobre a gratuidade do evento.

Após ação foram confirmadas as presenças de dezoito representantes da rede hoteleira de seis hotéis diferentes. Este número, apesar de não ser considerado satisfatório para o total de hotéis encontrados em Palmas, optou-se em manter o evento por considerar que atingir-se-ia o público interessado, podendo após isso realizar capacitações in loco. 


\section{O N V I T E}

O diretor do Campus Palmas, do Instituto Federal do Tocantins (IFTO), Wendell Eduardo Moura Costa, tem a honra de convidá-lo (la) para a palestra "Implementação na rede hoteleira do sistema de gestão da sustentabilidade em atendimento NBR 15.401: viabilidade e eficácia". A palestra é gratuita e será ministrada pela professora Dra. Mary Senna, juntamente com a estudante de Iniciação Científica Ana Julyah Valtuille. O momento ocorrerá nas datas e horários seguintes:

Data: 15 de abril às 19 horas

Data: 16 de abril às 10 horas

Data: 17 de abril às 14 horas

Local: Laboratório de Hospedagem do Campus Palmas

(AE 310 Sul, Avenida LO 05, s/n, Plano Diretor Sul)

\section{Mais informações}

O Campus Palmas concentra esforços para estar em consonância com os Objetivos do Milênio da ONU, dentre eles a busca por qualidade de vida das populações e o respeito ao meio ambiente. Com este objetivo, a unidade promoverá a palestra "Implementação na rede hoteleira do sistema de gestão da sustentabilidade em atendimento NBR 15.401: viabilidade e eficácia". As vagas são limitadas e haverá certificação aos participantes. Garanta sua participação pelo (63) 98480-8028.

INSTITUTO FEDERAL

Tocantins
MINISTÉRIO DA EDUCAÇÃO

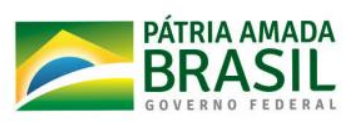

Figura 3: Carta convite aos hotéis.

Fonte: Dados da pesquisa. 


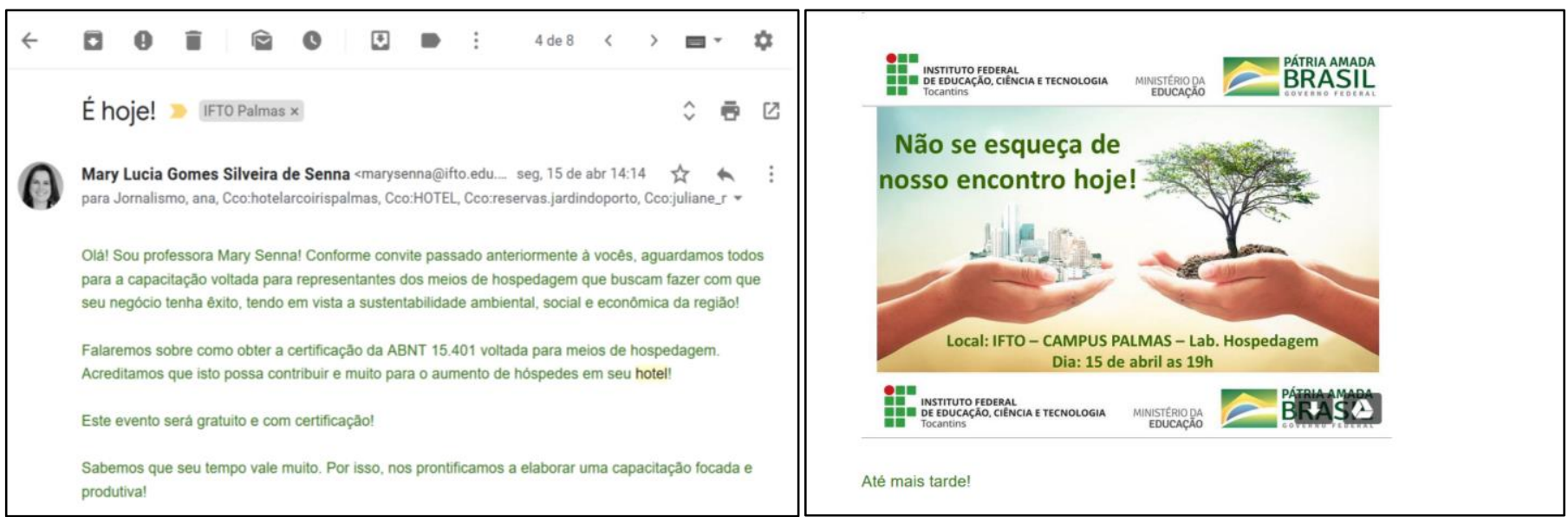

Figura 4: Lembrete final convite palestra. Fonte: Dados da pesquisa.

Foram preparadas 45 pastas informativas para o evento. Na pasta continha os seguintes itens preparados para a entrega aos envolvidos (Figuras 5 e 6):

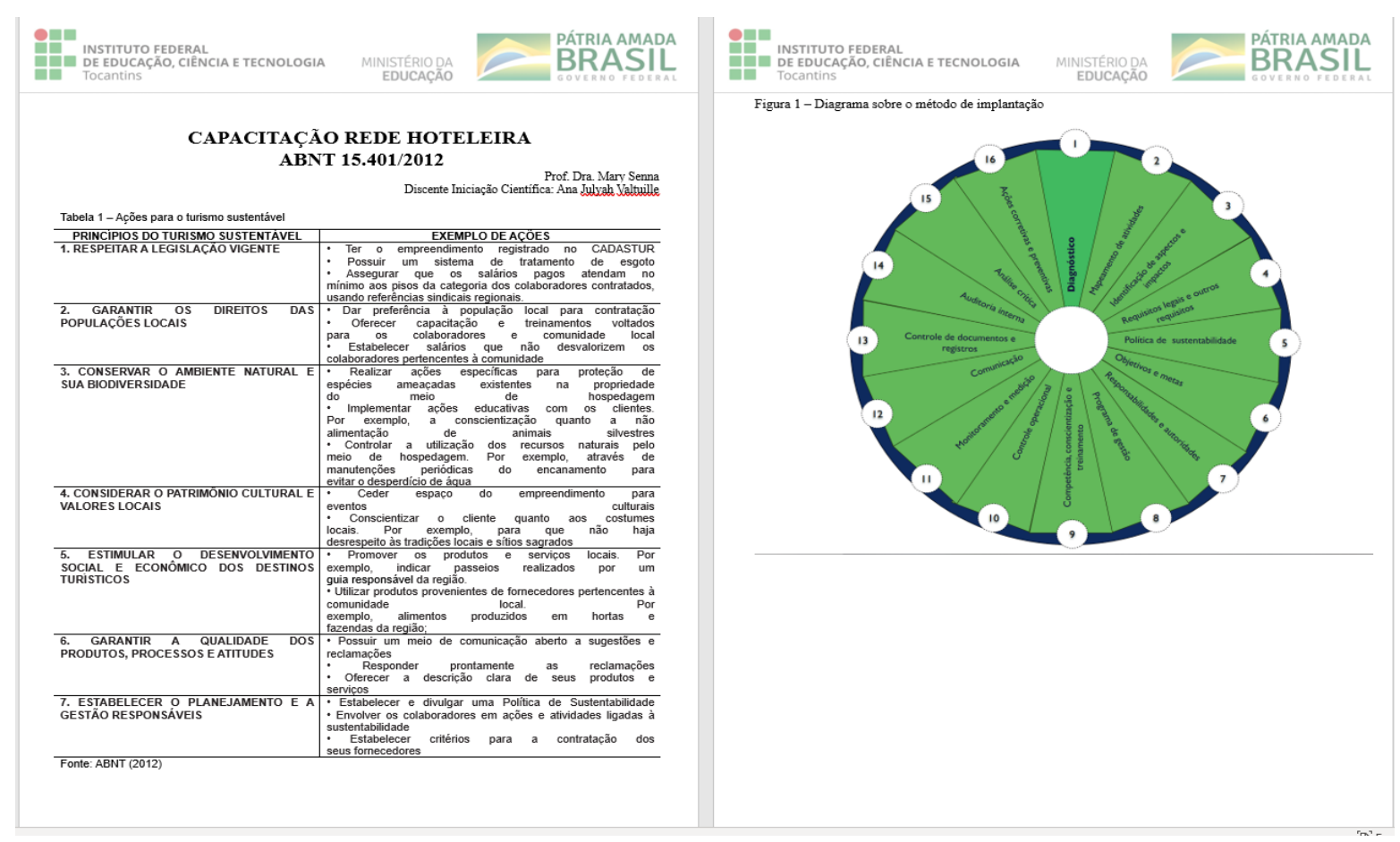

Figura 5: Encarte entregue em pasta para gestores - Parte 1.

Fonte: Dados da pesquisa.

Revbea, São Paulo, V. 15, № 1: 360-378, 2020 


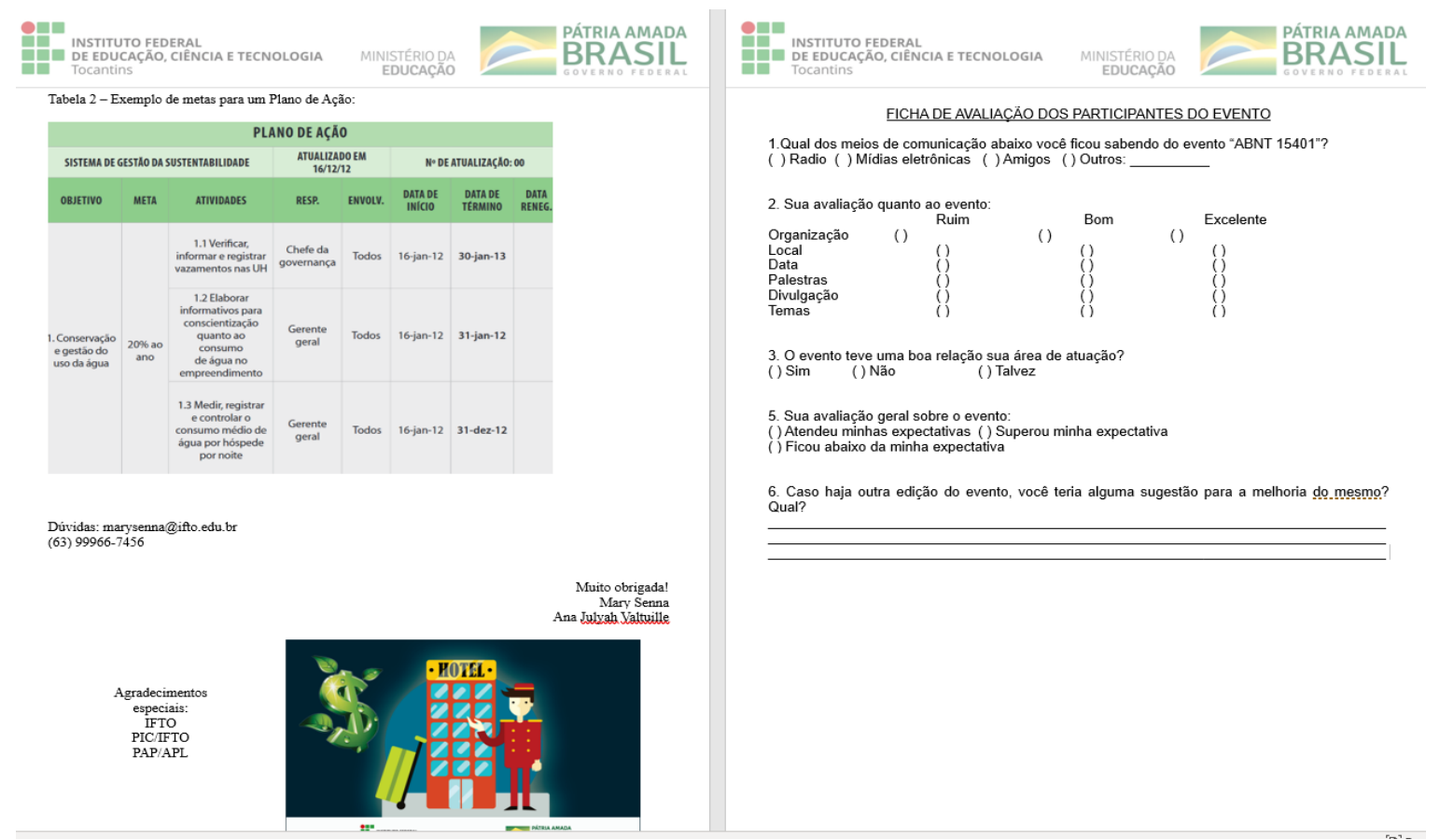

Figura 6: Encarte entregue em pasta para gestores - Parte 2.

Fonte: Dados da pesquisa.

No entanto, na data marcada para a capacitação não houve o comparecimento deles. Não vieram nenhum dos hotéis já confirmados. Isto corrobora com outra ação ambiental realizada para público diferente, mas também ligado a turismo em que não houve o comparecimento expressivo dos participantes (SENNA; DUTRA; MESSETTI, 2015, p.78). Isto levou a equipe organizadora a mudar a estratégia de ação. Foi decidido então que seria modificado o plano de trabalho, de modo agora a agendar um horário com cada hotel e fazer a visita in loco. Nesta nova configuração não foi com o nível de detalhamento que o curso de 4 horas seria, pois teríamos mais tempo para debater e propor ações mais eficazes. Mas, em virtude de sua realizar ser no ambiente de trabalho.

Vale destacar que, devido a esta mudança no plano de trabalho, foram selecionados os principais hotéis que apareciam com classificação acima de 7 no site Booking por considerar que estes mais facilidade em aderir as possíveis adequações solicitadas pela ABNT 15.401. Foi então agendada com os gerentes ou proprietários que pudessem receber a equipe de capacitação sem comprometer o ambiente de trabalho. Alguns (15\% da amostra total), por considerarem-se de menor porte, não se interessaram pela capacitação e não quiseram agendar. Mas na grande maioria das ligações houve interesse, seguindo-se assim para a marcação.

A duração média de cada visita foi de 30 minutos. Ao todo foram visitados 30 estabelecimentos do setor de hospedagem (62\% da amostra total). Em sua maioria fomos recebidos pelo gerente ou proprietário, e em alguns casos pelos dois profissionais simultaneamente. Em todos houve boa receptividade, mas em 
alguns hotéis (10\%) não foi possível realizar a capacitação diretamente com estes profissionais, sendo realizada capacitação com o funcionário da recepção e estando este comprometido em repassar as informações para os gestores Figuras 7 a 12).

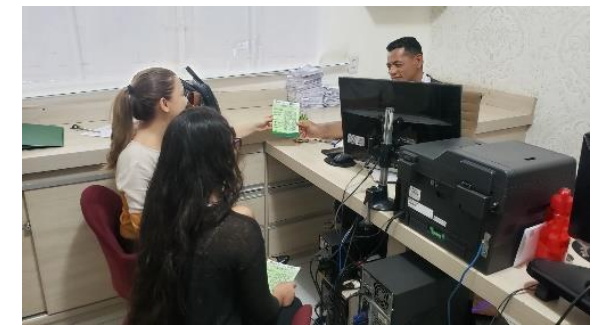

Figura 7: Capacitação Hotel 1. Fonte: Dados da pesquisa

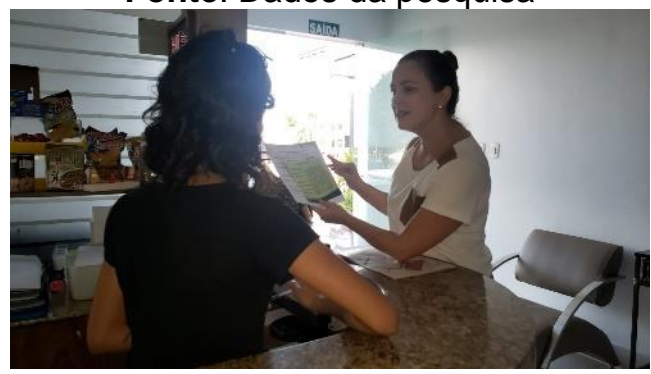

Figura 9: Capacitação Hotel 1. Fonte: Dados da pesquisa

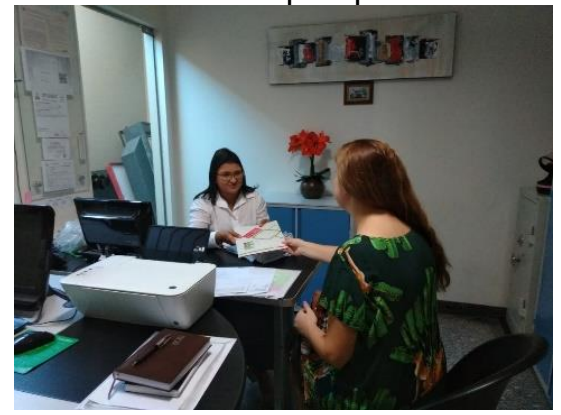

Figura 11: Capacitação Hotel 1. Fonte: Dados da pesquisa.

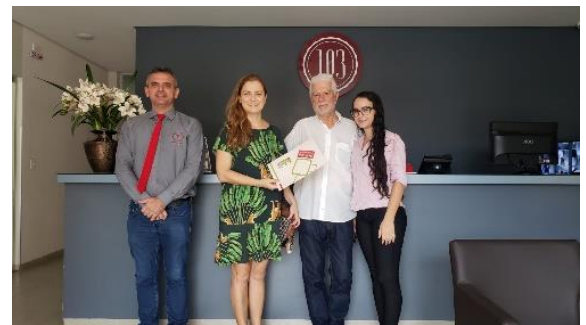

Figura 8: Capacitação Hotel 2.

Fonte: Dados da pesquisa

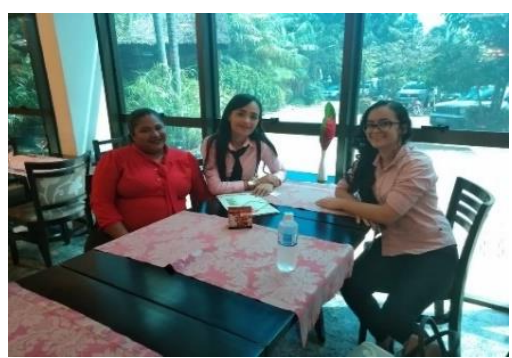

Figura 10: Capacitação Hotel 2. Fonte: Dados da pesquisa

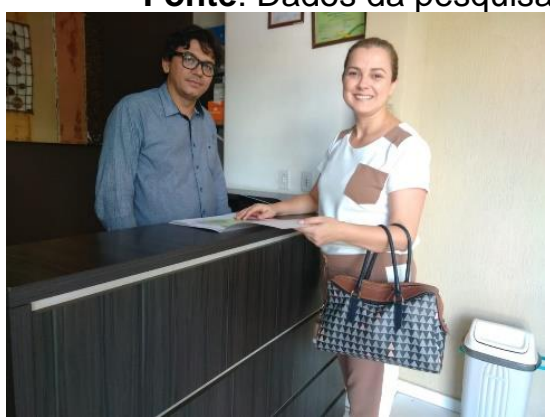

Figura 12: Capacitação Hotel 2. Fonte: Dados da pesquisa.

Durante a capacitação foi perguntado sobre a existência dos sistemas sustentáveis dos hotéis, bem como, foi realizada a observação das instalações dos mesmos, ainda que não fosse o objetivo de estudo deste trabalho.

Por meio de observação direta ou entrevista informal, percebeu-se que a maioria dos hotéis selecionados já possuem alguns dos itens exigidos pela ABNT 15401 para considerar o estabelecimento sustentável, tais como: energia solar, tratamento de esgoto, aproveitamento de água da chuva, Jardim de flora nativa e interruptor a cartão. Os resultados são apresentados na Figura 13. Os que não os tem, demonstraram interesse em sua implantação. Isto reforça que os hotéis 
de Palmas entrevistados possuem interesse em buscar formas de envolver-se em ações em prol do meio ambiente. Tal como Machado e Sousa (2018, p.33) destacam, hoje há uma busca pelo consumidor, de um estabelecimento que deixe a impressão positiva e duradoura na sua vida, ao combinar arquitetura de baixo impacto no meio ambiente, valorização cultural das regiões, bem como a sustentabilidade e ações de responsabilidade social.

\section{Implantação de Sistemas Sustentaveis}

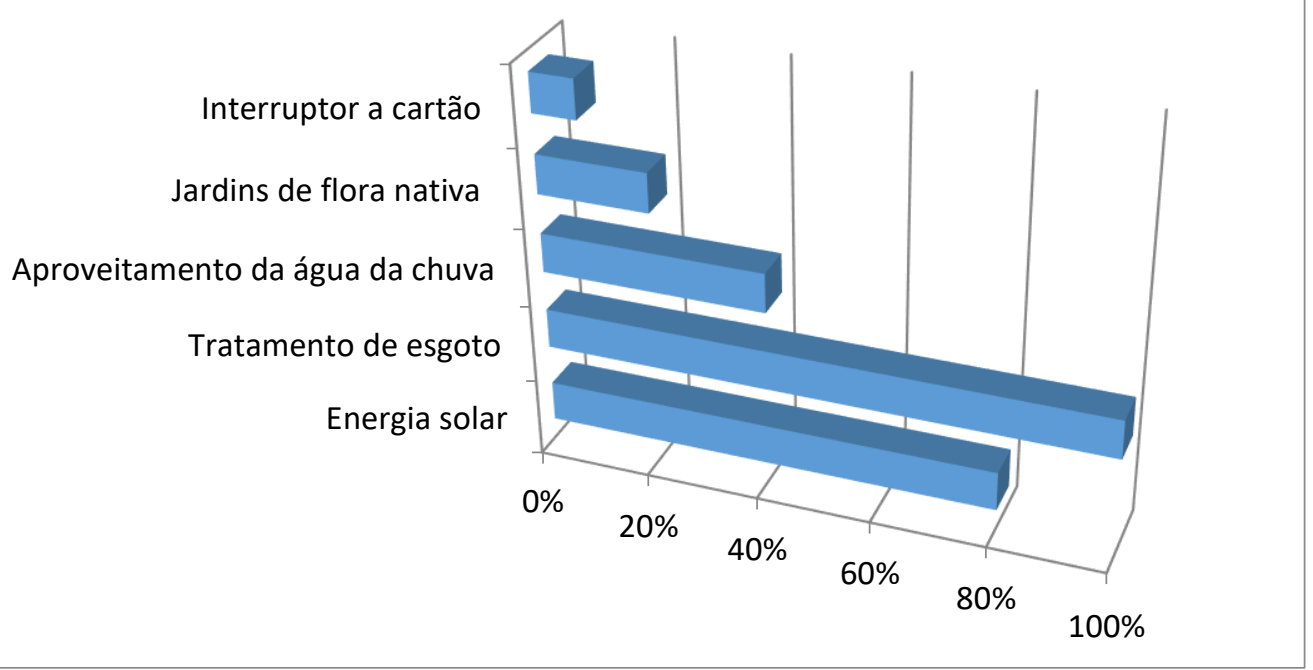

Figura 13: Implantação de sistemas sustentáveis.

Fonte: Dados da pesquisa.

Ao final da pesquisa foi possível notar que os hotéis de grande porte têm de projetos de energia solar ou quando não possuem já estão começando a instalação. Isto pode gerar uma redução dos custos financeiros e redução dos impactos ambientais. Lopes (2014 apud NISHIMOTO; VARAJÃO, 2018, p.152) destaca em seus estudos a importância do planejamento energético nos meios de hospedagem, buscando a utilização de energia limpa e renovável, evitando assim que a sazonalidade do fluxo de turistas não cause transtornos à cidade e aos seus moradores. Sabe-se que a implantação desses projetos em maior número em Palmas é bem recente, o que o torna com um custo bem elevado. Mas em toda a capacitação buscou-se demonstrar os pontos positivos desta ação em um estado com abundância de energia solar.

De acordo com os gestores, com a instalação de placas solares o custo de energia, com a atual fornecedora de energia cairia mais de $90 \%$. Essa economia garante que no máximo em 3 anos já tenham o retorno esperado, e utilizem apenas energia limpa sem danos ao meio ambiente. Logo, tornando-se eficiente este tipo de instalação a médio prazo. 
No que tange ao sistema de esgoto, percebeu-se que está presente em $100 \%$ dos hotéis. Quanto ao aproveitamento da água da chuva $40 \%$, jardins com presença de flora nativa $20 \%$ e interruptor a cartão apenas $8 \%$, o que demonstra que ainda se faz necessária a efetivação de ações como esta para adquirir o selo verde.

Outro recurso que a maioria dos hotéis têm é o aproveitamento da água de chuva, além de resultar em economia de água potável, contribui também para mitigar problemas relacionados com a escassez de recursos hídricos. É uma forma de uso mais racional da água potável e de se evitar seu uso para fins não potáveis, reduzindo a pressão sobre os mananciais.

A Norma NBR 15.401 (Brasil - 2006) orienta os meios de hospedagem na busca de caminhos alternativos para a sustentabilidade. O diagnóstico é fundamental para que sejam constatados todos os impactos que estão atrelados aos serviços oferecidos pelo hotel e para que as medidas de minimização e mitigação sejam planejadas de acordo com os objetivos e metas a serem alcançados pelo meio de hospedagem. Os impactos negativos advindos da construção e operação do setor hoteleiro são principalmente refletidos no meio ambiente.

\section{Considerações Finais}

Não se pode negar que a principal dificuldade em executar a ação de Educação Ambiental foi a falta de interesse do público alvo. Acredita-se que esta falta de interesse possa estar ligada à não importância dada aos assuntos relativos a conservação ambiental, mesmo atrelando isto à economia de gastos, sejam energéticos ou de desperdício, ou ainda ao aumento no número de hóspedes que busquem hospedar-se em locais que tenha esta preocupação em preservar o meio ambiente.

Sabemos que a rotina de um hotel é exaustiva e por vezes impossibilite a recepção de capacitações ou visitas que venham a fugir da rotina diária. Mas as capacitações no setor se fazem necessárias constantemente, pois são nelas que vemos o que tem sido discutido de mais recente no setor. Principalmente capacitações gratuitas e de órgãos que tenham relevância científica para tal.

Mas ao mesmo tempo percebeu-se que, apesar da mudança na estratégia inicial, os resultados tiveram um saldo positivo. A ida até os locais visitados proporcionou uma vivência e entendimento dos desafios enfrentados e que tipos de adaptações estão sendo tomadas por eles.

Mesmo que alguns não tenha interesse em adquirem o selo de gestão sustentável responsável, notou-se que a maioria já tem capacidade de preencher os requisitos solicitados pela ABNT NBR 15.401, sem precisarem investir muito financeiramente, pois já possuem o princípio da gestão sustentável. 
Percebeu-se também que a mudança no plano de pesquisa proporcionou um contato mais direto com o público, atingindo assim o objetivo proposto, despertando na maioria dos participantes desejo em adquirir o selo de gestão sustentável

\section{Referências Bibliográficas}

ABNT - Associação Brasileira de Normas Técnicas. (2004). NBR ISO 14001:2004-Sistema de gestão ambiental -Requisitos com diretrizes para uso. São Paulo: 2004.

ABNT. NBR 15401: Meios de hospedagem - Sistema de gestão da sustentabilidade - Requisitos Parceria ABNT e Ministério do Turismo - Normas para o desenvolvimento do Turismo no Brasil. p. 1-22, 2006.

ASSUNÇÃO, R.; AMORIM, T.; MONDO, T. S. Sustentabilidade Em Meios De Hospedagem: Estudo De Caso Em Meio De Hospedagem De Garopaba. Anais do $2^{\circ}$ Simpósio de Integração Científica e Tecnológica do Sul Catarinense SICT-Su, n. 2010, p. 278-289, 2013.

BARBOSA, S. SILVA, T. Análise de impactos ambientais nos equipamentos hoteleiros: Um estudo de caso em hotéis de pequeno e médio porte em Palmas - Tocantins. TCC. Graduação em Tecnologia em Gestão de Turismo, 2018

BERNADELLI, J.M. J., et al., 2014. Sistemas de Gestão Ambiental na Operação dos Empreendimentos Hoteleiros. Revista Rosa dos Ventos , v.6 n.4 , pp. 564582, out - dez, 2014.

BORGES, C. H. L., FERRAZ, M.I.F.; BORGES, A.V.B. Turismo sustentável e meios de hospedagem: uma avaliação da sustentabilidade hoteleira em Barra Grande, Maraú (BA). Revista turismo - visão e ação - eletrônica, v. 17, n. 3, p. 601-629, 2015.

BRANDAO, C. D. N.; BARBIERI, J. C.; REYES JUNIOR, E. Análise da sustentabilidade do turismo: um estudo em comunidades indígenas no Estado de Roraima, Brasil. Revista Brasileira de Pesquisa em Turismo, v. 9, n. 3, p. 500, 2015.

CASTRO, L. L.C.; PINTO, R. Sustentabilidade e turismo comunitário: aspectos teórico-conceituais. Caderno Virtual de Turismo. Rio de Janeiro, v. 13, n. 2., p.213-226, ago. 2013.

CORDEIRO, I.; KÖRÖSSY, N. Quando as políticas públicas de turismo sustentável ignoram a dimensão social: reflexões a partir do estudo de caso de Fernando de Noronha. Caderno Virtual de Turismo - Rio de Janeiro, v.18, n.3, p.42-58, dez. 2018. 
DERANI, C. Educação Ambiental: Um processo acadêmico? In: RODRIGUES, H.W.; DERANI, C. (org.). Educação Ambiental. Coleção: Pensando o Direito no Século XXI. Vol. I. Florianópolis: Editora Fundação Boiteux, 2011. Disponível em <http://funjab.ufsc.br/wp/?page id=1819> Acesso em: 30/08/2019.

FERREIRA, L.C.; MARTINS, L.C.G.F.; PEREIRA, S.C.M; RAGGI, D.G.; SILVA, J.G.F. Educação Ambiental e Sustentabilidade na prática escolar. Revista Brasileira de Educação Ambiental, São Paulo, ano 2019, v. 14, n. 2, 201-214, 2019.

GIL, A.C. Métodos e técnicas de pesquisa social. São Paulo: Atlas, 1999.

GRAEL, P.F.F.; OLIVEIRA, O.J. Sistemas certificáveis de gestão ambiental e da qualidade: práticas para integração em empresas do setor moveleiro. Produção, São Paulo, v. 20, n. 1, p. 30-41, Mar. 2010.

LADWIG, N. I. O Sistema de Informação Geográfica para o planejamento e a gestão sustentável do turismo. Revista Gestão \& Sustentabilidade

Ambiental, v. 1, n. 1, p. 19, 2012.

LEITE, J.R.M. Sociedade de risco e estado. In: CANOTILHO, J.J.G.; LEITE, J.R.M. (org.). Direito constitucional ambiental brasileiro. 5 ed. São Paulo: Saraiva, 2012 (p. 157-232). RAM, Rev. Adm. Mackenzie (Online) vol.12 no.3 São Paulo June 2011.

MACHADO, A.F., SOUSA, B. Luxo Sustentável em Contextos de Hotelaria e Turismo: Do diferencial competitivo à preocupação com a responsabilidade social. International Journal of Marketing, Communication and New Media. ISSN: 2182-9306. Special Issue 4 - Luxury Marketing, NOV 2018.

MORAES, A. A Certificação Ambiental dos Meios de Hospedagem: uma análise das motivações para a aplicação da certificação ambiental nos meios de hospedagem de Balneário de Camboriú. Turydes, Santa Catarina. v. 2., n. 6, nov./dez. 2009.

NISHIMOTO, E. VARAJÃO, G.F.D.C. Energia solar fotovoltaica em meios de hospedagem no Brasil: nicho de mercado ou tendência à massificação? CULTUR, ano 12 - no 01 - Fev/2018.

OLIVEIRA, T.P.P, SARAIVA, P.M. A Influência do Marketing Digital no Perfil de Consumo da Geração Y. Revista Multidisciplinar e de Psicologia. v.13, n. 44, p. 589-600, 2019.

PAULA, K.M.R. Inovação e competitividade na hotelaria: um estudo multicasos no setor hoteleiro de Palmas-TO. TCC. Trabalho de Conclusão de Curso. Curso Superior de Tecnologia em Gestão de Turismo. Instituto Federal de Educação, Ciência e Tecnologia do Tocantins, 2018. 
PEREIRA, L. Oportunidades e desafios da prática do marketing verde no setor hoteleiro de pequeno porte. São Paulo, 2016. 104 p. Dissertação (Mestrado em Administração) - Pontifícia Universidade Católica de São Paulo, São Paulo, 2016.

PERES JR., M. R.; REZENDE, D. C. Gestão da sustentabilidade no segmento hoteleiro: estudo dos meios de hospedagem de Monte Verde, MG. Caderno Virtual de Turismo, v. 11, p. 234-252, 2011.

PINTO, R. Sustentabilidade e turismo comunitário: aspectos teórico-conceituais. Caderno Virtual de Turismo, v. 13, n. 2, p. 213-226, 2013.

REZENDE, C. F. Rezende, D.C. Impactos do Turismo: Uma Análise Sob a Ótica da População Receptora. ANPAD, 2015.

SENNA, M.L.G.S.A aplicabilidade do índice de qualidade de vida, da pegada ecológica do turismo e dos indicadores de sustentabilidade da organização das nações unidas para destinos turísticos de pequeno porte: um estudo de caso no Jalapão - TO, Tese. Universidade de São Paulo, Doutorado em Ciências pelo Instituto Pesquisa Energéticas e Nucleares, 2016.

SENNA, M.L.G.S., DUTRA, V.C., MESSETTI, P.H.S. Capacitando em turismo para o bem receber: plano de desenvolvimento da APL de turismo do Jalapão Mateiros/TO. Desafios: Revista Interdisciplinar da Universidade Federal do Tocantins - V. 1 - n. 02. p. 70-82, jan/jun. 2015.

SERENO, M.A.B. et al. Proposta para diretrizes de gestão ambiental para atividade hoteleira no Brasil. Revista Gestão Industrial, v. 11, n. 01: p. 6991, dez.2014

SILVA, N.C.; CÂNDIDO, G.A. Sistema de indicadores de sustentabilidade do desenvolvimento do turismo: um estudo de caso do município de Areia -- PB. Revista Brasileira de Pesquisa em Turismo, v. 10, n. 3, p. 475-496, 2016. 